\title{
Real-world experience of first-line afatinib in patients with EGFR-mutant advanced NSCLC: a multicenter observational study
}

Gwo-Fuang $\mathrm{Ho}^{1 *}$, Chee-Shee Chai ${ }^{2}$, Adlinda Alip ${ }^{1}$, Mohd Ibrahim A. Wahid ${ }^{3}$, Matin Mellor Abdullah", Yoke-Ching Foo ${ }^{4}$, Soon-Hin How ${ }^{5}$, Adel Zaatar ${ }^{6}$, Kai-Seng Lam${ }^{7}$, Kin-Wah Leong ${ }^{6}$, John-Seng-Hooi Low ${ }^{7}$, Mastura Md Yusof ${ }^{7}$, Erica Chai-Yong Lee ${ }^{1}$, Yok-Yong Toh ${ }^{1}$ and Chong-Kin Liam ${ }^{8}$

\begin{abstract}
Background: This study aimed to evaluate the efficacy, side-effects and resistance mechanisms of first-line afatinib in a real-world setting.

Methods: This is a multicenter observational study of first-line afatinib in Malaysian patients with epidermal growth factor receptor (EGFR)-mutant advanced non-small cell lung cancer (NSCLC). Patients' demographic, clinical and treatment data, as well as resistance mechanisms to afatinib were retrospectively captured. The statistical methods included Chi-squared test and independent t-test for variables, Kaplan-Meier curve and log-rank test for survival, and Cox regression model for multivariate analysis.
\end{abstract}

Results: Eighty-five patients on first-line afatinib from 1st October 2014 to 30th April 2018 were eligible for the study. EGFR mutations detected in tumors included exon 19 deletion in 80.0\%, exon 21 L858R point mutation in $12.9 \%$, and rare or complex EGFR mutations in $7.1 \%$ of patients. Among these patients, $18.8 \%$ had Eastern Cooperative Oncology Group performance status of 2-4, 29.4\% had symptomatic brain metastases and 17.6\% had abnormal organ function.

Afatinib $40 \mathrm{mg}$ or $30 \mathrm{mg}$ once daily were the most common starting and maintenance doses. Only one-tenth of patients experienced severe side-effects with none having grade 4 toxicities. The objective response rate was $76.5 \%$ while the disease control rate was 95.3\%. At the time of analysis, 56 (65.9\%) patients had progression of disease (PD) with a median progression-free survival (mPFS) of 14.2 months ( $95 \% \mathrm{Cl}, 11.85-16.55$ months). Only $12.5 \%$ of the progressed patients developed new symptomatic brain metastases. The overall survival (OS) data was not mature. Thirty-three (38.8\%) patients had died with a median OS of 28.9 months ( $95 \% \mathrm{Cl}, 19.82-37.99$ months). The median follow-up period for the survivors was 20.0 months (95\% Cl, 17.49-22.51 months).

Of patients with PD while on afatinib, 55.3\% were investigated for resistance mechanisms with exon 20 T790 M mutation detected in $42.0 \%$ of them.

Conclusions: Afatinib is an effective first-line treatment for patients with EGFR-mutant advanced NSCLC with a good response rate and long survival, even in patients with unfavorable clinical characteristics. The side-effects of afatinib were manageable and $T 790 \mathrm{M}$ mutation was the most common resistance mechanism causing treatment failure.

Keywords: Afatinib, Dose adjustment, Epidermal growth factor receptor (EGFR), Real-world, Tyrosine kinase inhibitor

\footnotetext{
*Correspondence: gwoho@um.edu.my

${ }^{1}$ Department of Clinical Oncology, Faculty of Medicine, University of Malaya,

Kuala Lumpur, Malaysia

Full list of author information is available at the end of the article
}

(c) The Author(s). 2019 Open Access This article is distributed under the terms of the Creative Commons Attribution 4.0 International License (http://creativecommons.org/licenses/by/4.0/), which permits unrestricted use, distribution, and reproduction in any medium, provided you give appropriate credit to the original author(s) and the source, provide a link to the Creative Commons license, and indicate if changes were made. The Creative Commons Public Domain Dedication waiver (http://creativecommons.org/publicdomain/zero/1.0/) applies to the data made available in this article, unless otherwise stated. 


\section{Background}

Epidermal growth factor receptor (EGFR)-tyrosine kinase inhibitor (TKI) is the recommended first-line treatment for patients with advanced non-small cell lung cancer (NSCLC) harboring somatic driver mutation in the EGFR gene [1]. Several phase III clinical trials have reported promising median progression-free survivals (mPFS) (9-13 months) and tolerable side-effects in patients with EGFR-mutant advanced NSCLC receiving first-generation EGFR-TKIs [2-6].

Afatinib is an irreversible, second-generation EGFRTKI that has been shown to be more potent than platinum doublet chemotherapies as well as the firstgeneration EGFR-TKIs, such as gefitinib and erlotinib [7-10]. In the LUX-Lung 7 study, patients receiving first-line afatinib for EGFR mutant advanced NSCLC had significantly longer mPFS and median time-totreatment failure than those on first-line gefitinib [9]. In LUX-Lung 8, patients receiving second-line afatinib for advanced squamous cell carcinoma of lung had significantly longer mPFS and median overall survival (mOS) than those on second-line erlotinib [10]. Since afatinib targets all homo-dimers and hetero-dimers of the ErbB family (EGFR/ErbB1, HER2/ErbB2, ErbB3, and ErbB4), it is more efficacious than first-generation EGFRTKIs [11, 12]. At the same time, the broad spectrum of activity and irreversible mechanism of action of afatinib also lead to more treatment related side-effects.

Patients with rare or complex EGFR mutation, symptomatic brain metastases, poor Eastern Cooperative Oncology Group (ECOG) performance status and inadequate organ function are routinely excluded from clinical trials. Nevertheless, these unfavourable characteristics are commonly encountered in clinical practice. Therefore, this study aimed to look into the efficacy and side-effects of first-line afatinib in the real-world setting. In addition, the mechanisms of acquired resistance causing first-line afatinib failure were analyzed.

\section{Methods}

\section{Study design and patients}

This is a multicenter observational study of Malaysian patients with EGFR-mutant advanced NSCLC started on first-line afatinib treatment at the University of Malaya Medical Center, Subang Jaya Medical Center, Beacon International Specialist Hospital, Pantai Hospital Kuala Lumpur, Gleneagles Hospital Penang and Hospital Tengku Ampuan Afzan Kuantan from 1st October 2014 to 30th April 2018. All patients analyzed were aged 18 years and above, had histologically confirmed locally advanced (stage IIIB) or metastatic (stage IV) NSCLC and had EGFR mutation detected in the pre-treatment biopsy specimens. Patients were excluded if they had previous cytotoxic chemotherapy or targeted therapy.
Patients with symptomatic brain metastases and inadequate organ function were not excluded. The study was approved by the ethics committees of the respective hospitals that also granted an informed consent waiver.

\section{Procedure}

Eligible patients were retrospectively identified from the lung cancer databases and pharmacy dispensing records of the respective hospitals. The patients' demographic, clinical, and treatment data, as well as resistance mechanisms to afatinib were extracted from their case records. A never smoker was defined as one with lifetime cigarette smoking of less than 100 sticks [13]. The patients' organ function at diagnosis was graded according to Common Terminology Criteria for Adverse Events version 4 (CTCAE v4.0) for blood, renal and liver function [14]. Initial tumor biopsy specimens of the patients were tested for EGFR mutations using the $\operatorname{cobas}^{\oplus}$ EGFR Mutation Test v2 (Roche Molecular Systems, New Jersey, USA), or peptic nucleic acidlocked nucleic acid polymerase chain reaction (PCR) clamp method, PNAClamp ${ }^{\mathrm{TM}}$ EGFR Mutation Detection Kit (PANAGEN, Daejon, Korea). Baseline computed tomography (CT) examination of the thorax, abdomen and pelvis (TAP) was performed in every patient at diagnosis. CT-brain was performed in those with neurological symptoms or signs. The patient's NSCLC was staged according to the 7th edition of the American Joint Committee on Cancer [15]. Tumor response was evaluated by performing a repeat CT-TAP 4 weeks after the initiation of afatinib, and subsequently, once every 12 weeks until disease progression or symptomatic deterioration, whichever occurred earlier. Tumor response was categorized according to the Response Evaluation Criteria in Solid Tumors version 1.1 [16].

Patients received afatinib at starting doses of $40 \mathrm{mg}$, $30 \mathrm{mg}, 25 \mathrm{mg}$ or $20 \mathrm{mg}$ once daily. Afatinib $40 \mathrm{mg}$ once daily is the recommended starting dose. Afatinib at $30 \mathrm{mg}$ once daily was only started in patients with exon 19 deletion or exon $21 \mathrm{~L} 858 \mathrm{R}$ point mutation who did not have symptomatic brain metastases. Afatinib $20 \mathrm{mg}$ once daily and $25 \mathrm{mg}$ once daily were derived by dividing the $40 \mathrm{mg}$ and $50 \mathrm{mg}$ tablets into halves, respectively. These adjusted dosages were only given to patients who were financially constrained to self-purchase the drug. The maintenance dose of afatinib ranged from 20 to $50 \mathrm{mg}$ once daily depending on the patients' clinical response and tolerability. The optimum dose of afatinib was defined as the dose that could control the patient's disease alongside tolerable side-effects for the patient. Afatinib was given until symptomatic disease progression or occurrence of intolerable side-effects. Only common side-effects documented during clinic visits 
such as diarrhea, stomatitis, skin rash, acne, paronychia and fatigue were assessed and graded according to CTCAE v4.0 [14]. Second-line treatment was offered when patients experienced symptomatic disease progression confirmed by CT scan or intolerable side-effects from afatinib. At any time, patients with symptomatic brain metastases were offered surgical resection, whole brain radiotherapy or stereotactic radiotherapy for brain lesions based on the decision of the multidisciplinary team in the respective centers.

Investigations for acquired exon $20 \mathrm{~T} 790 \mathrm{M}$ mutation and histological transformation were only performed in patients who had PD after 31st December 2015 when early access to the third-generation EGFR-TKI, osimertinib became available. Investigation for $T 790 \mathrm{M}$ mutation involved tissue re-biopsy or liquid biopsy. The former utilized the similar EGFR mutation detection technique as at initial diagnosis; while for the latter peptic nucleic acid-locked nucleic acid polymerase chain reaction (PCR) clamp method (PANAGEN, Daejon, Korea) or p-EGFR droplet digital PCR-based technology (Sanomics, Hong Kong, China) was used.

\section{Statistical analysis}

Categorical variables were expressed as percentages while continuous variables were expressed as mean \pm standard deviation (SD) or median with range depending on the normality of distribution of the variables. KaplanMeier methodology was used to determine the mPFS and mOS. Differences between categorical variables were tested using Chi-Squared test or Fisher Exact test. For continuous variables, the differences were compared using independent $\mathrm{t}$-test or Mann-Whitney $\mathrm{U}$ test. Multivariate analysis was performed using logistic regression. A p-value of $<0.05$ was considered statistically significant. Statistical analyses were performed by using the software package, Statistical Package for the Social Sciences (SPSS for Windows version 23.0, SPSS Inc., Chicago, IL, USA).

\section{Results}

\section{Demographic and clinical characteristics}

A total of 85 patients who met the study criteria were included (Fig. 1). Their demographic and clinical characteristics are shown in Table 1 . The majority of the

- 70 patients had second-line afatinib

- 35 patients had third-line afatinib

- 34 patients had forth-line afatinib

- 8 patients had fifth-line afatinib

14 patients excluded from the study:

- 3 patients did not have Epidermal Growth Factor Receptor mutation detected in initial biopsy

- 6 patients lost to follow-up

- 5 patients had incomplete medical records 
Table 1 Demographic and clinical characteristics of patients

\begin{tabular}{|c|c|}
\hline Demographic and clinical characteristic & $\begin{array}{l}\text { No. of patients } \\
(n=85)\end{array}$ \\
\hline \multicolumn{2}{|l|}{ Age, year } \\
\hline Mean (+ SD) & $59.1+10.8$ \\
\hline \multicolumn{2}{|l|}{ Gender, No. (\%) } \\
\hline Female & $47(55.3)$ \\
\hline Male & $38(44.7)$ \\
\hline \multicolumn{2}{|l|}{ Ethnicity, No. (\%) } \\
\hline Chinese & $63(74.1)$ \\
\hline Non-Chinese (Malay and Indian) & $22(25.9)$ \\
\hline \multicolumn{2}{|l|}{ Smoking history, No. (\%) } \\
\hline Never smoker & $67(78.8)$ \\
\hline Previous or current smoker & $18(21.2)$ \\
\hline \multicolumn{2}{|l|}{ ECOG performance status at diagnosis, No. (\%) } \\
\hline ECOG 0-1 & $69(81.2)$ \\
\hline ECOG 2-4 & $16(18.8)$ \\
\hline \multicolumn{2}{|l|}{ Tumor histology, No. (\%) } \\
\hline Adenocarcinoma & $82(96.5)$ \\
\hline Squamous cell carcinoma & $3(3.5)$ \\
\hline \multicolumn{2}{|l|}{ Tumor stage, No. (\%) } \\
\hline$\| I B$ & $4(4.7)$ \\
\hline IV & $81(95.3)$ \\
\hline \multicolumn{2}{|l|}{ Symptomatic baseline brain metastases, No. (\%) } \\
\hline No & $60(70.6)$ \\
\hline Yes & $25(29.4)$ \\
\hline -Parenchymal metastases & $16(64.0)$ \\
\hline -Leptomeningeal metastases & $7(28.0)$ \\
\hline -Both parenchymal and leptomeningeal metastases & $2(8.0)$ \\
\hline \multicolumn{2}{|l|}{ Abnormal organ function, No. (\%) } \\
\hline No & $70(82.4)$ \\
\hline Yes & $15(17.6)$ \\
\hline -Blood & $5(33.3)$ \\
\hline -Renal & $9(60.0)$ \\
\hline -Liver & $2(13.3)$ \\
\hline \multicolumn{2}{|l|}{ EGFR mutation subtype, №. (\%) } \\
\hline Exon 19 deletion & $68(80.0)$ \\
\hline Exon 21 L858R point mutation & $11(12.9)$ \\
\hline Rare or complex mutations & $6(7.1)$ \\
\hline -Exon 18 G719X & $2(33.1)$ \\
\hline -Exon 18 G719X and exon 20 S768I & $1(16.7)$ \\
\hline -Exon 18 G719X and exon 20 T790 M & $1(16.7)$ \\
\hline -Exon 19 deletion and exon 20 insertion & $1(16.7)$ \\
\hline -Exon 20 insertion & $1(16.7)$ \\
\hline
\end{tabular}


patients were female, never smokers and of Chinese ethnicity. Eighty-two (96.5\%) patients had lung adenocarcinoma while the remaining had squamous cell carcinoma. The EGFR mutations harbored by the tumors included exon 19 deletion in 80.0\%, exon $21 \mathrm{~L} 858 \mathrm{R}$ point mutation in $12.9 \%$, and rare or complex EGFR mutations in $7.1 \%$ of the patients. The ECOG performance status was $2-4$ in $18.8 \%$, symptomatic baseline brain metastases were present in $29.4 \%$, and abnormal organ function at baseline was present in $17.6 \%$ of the patients.

\section{Afatinib starting dose, dose adjustment and optimal dose and treatment of baseline brain metastases}

Most of the patients were started on afatinib $40 \mathrm{mg}$ once daily (52.9\%), followed by $30 \mathrm{mg}$ once daily (35.3\%), 20 $\mathrm{mg}$ once daily (8.2\%) and $25 \mathrm{mg}$ once daily (3.5\%) (Table 2). The initial starting dose of afatinib could be maintained in more than half of the patients. Afatinib dose reduction was exclusively due to side-effects while dose escalation was because of inadequate treatment response. The optimum dose of afatinib was $40 \mathrm{mg}$ once daily or $30 \mathrm{mg}$ once daily in 35.7 and $35.7 \%$ of the patients, respectively. Of the 25 patients with baseline symptomatic brain metastases, $21(84.0 \%)$ had brain

Table 2 Afatinib starting dose, dose adjustment and optimal dose and treatment of baseline brain metastases

\begin{tabular}{ll}
\hline Treatment Pattern and Outcome & $\begin{array}{l}\text { Total number of patients } \\
(n=85)\end{array}$ \\
\hline Afatinib starting dose, No. (\%) & $45(52.9)$ \\
$40 \mathrm{mg}$ once daily & $30(35.3)$ \\
$30 \mathrm{mg}$ once daily & $3(3.5)$ \\
$25 \mathrm{mg}$ once daily & $7(8.2)$ \\
$20 \mathrm{mg}$ once daily & \\
Afatinib dose adjustment, No. (\%) & $49(57.6)$ \\
Starting dose maintained & $10(11.8)$ \\
Dose increased & $26(30.6)$ \\
Dose reduced & \\
Afatinib optimum dose, No. (\%) & $4(4.7)$ \\
50 mg once daily & $30(35.3)$ \\
40 mg once daily & $30(35.3)$ \\
30 mg once daily & $12(14.1)$ \\
25 mg once daily & $9(10.6)$ \\
20 mg once daily & \\
Brain metastasis treatment, No. (\%) & $60(70.6)$ \\
No brain metastases & $4(4.7)$ \\
Afatinib alone & $21(24.7)$ \\
Afatinib with surgery or radiotherapy &
\end{tabular}

radiotherapy or surgical resection of the brain lesions on top of the first-line afatinib (Table 2).

\section{Treatment outcome \\ Response to afatinib}

The objective response rate (ORR) was $76.5 \%$ while the disease control rate (DCR) was $95.3 \%$ on first-line afatinib (Table 3). Two (2.4\%) patients had complete response. The ORR and DCR according to EGFR mutation subtype, presence or absence of symptomatic brain metastases, ECOG performance status, presence or absence of abnormal organ function, afatinib dose adjustment and different optimal doses of afatinib are shown in Table 4. Patients without baseline symptomatic brain metastases had significantly better response to afatinib than those with symptomatic baseline brain metastases (81.7 versus $56.0 \%, p=0014$ ). On multivariate subgroup analyses involving the covariates as shown in Table 4, patients without symptomatic brain metastases had significantly higher ORR than that of those with symptomatic brain metastases (81.7 versus $56.0 \%$; OR, 4.51 ; $95 \%$ CI, 1.45-14.00; $\mathrm{p}=0.009$ ); while patients with afatinib dose reduction had significantly higher ORR than that of those without dose adjustment (88.5 versus $65.3 \%$, OR, 5.53; 95\% CI, 1.32-23.24; $p=0.019$ ).

\section{Progression-free survival}

The mPFS was 14.2 months (95\% CI, 11.85-16.55 months) with $56(65.9 \%)$ patients having PD at the time of analysis (Fig. 2). Only $12.5 \%$ of patients with PD experienced new symptomatic brain metastases while the remaining had PD at new sites other than the brain. The mPFS according to EGFR mutation subtype, presence or absence of symptomatic brain metastases, ECOG performance status, presence or absence of abnormal organ function, afatinib dose adjustment and different optimal doses of afatinib are shown in Table 5. On univariate analysis, only patients with exon 19 deletion had significantly longer mPFS compared to patients with exon 21 $L 858 R$ point mutation (16.0 versus 8.7 months; HR, 0.31 ; 95\% CI, 0.14-0.71; $\mathrm{p}=0.006)$ and rare or complex EGFR mutations (16.0 versus 9.0 months; HR, 0.34; 95\% CI, $0.13-0.94, p=0.037)$. On multivariate analysis, only the mPFS of patients with exon 19 deletion was significantly longer than the mPFS of patients with exon $21 \mathrm{~L} 858 \mathrm{R}$ point mutation (16.0 versus 8.7 months; HR, 0.27 ; $95 \%$ CI, 0.12-0.58; $p=0.001)$.

\section{Overall survival}

The mOS was 28.9 months (95\% CI, 19.82-37.99 months) (Fig. 3). Thirty-three (38.8\%) patients had died at the time of analysis while the median followup period for the survivors was 20.0 months (95\% CI, 17.49-22.51 months). 
Table 3 Treatment outcome to afatinib and resistance mechanism identified at disease progression

\begin{tabular}{lc}
\hline Treatment outcome & $\begin{array}{c}\text { Total number of patients } \\
(n=85)\end{array}$ \\
\hline Best tumor response, No. (\%) & $2(2.4)$ \\
Complete response & $63(74.1)$ \\
Partial response & $16(18.8)$ \\
Stable disease & $4(4.7)$ \\
Progressive disease & $29(34.1)$ \\
Disease progression site, No. (\%) & $7(8.2)$ \\
None & $49(57.6)$ \\
New brain lesions & $29(34.1)$ \\
New lesions at other sites & $25(29.4)$ \\
Investigation for resistance mechanism, No. (\%) & $31(36.5)$ \\
No progression & $13(42.0)$ \\
Not investigated & $18(58.0)$
\end{tabular}

Table 4 Univariate and multivariate analyses of ORR and DCR according to clinical and treatment characteristics

\begin{tabular}{|c|c|c|c|c|c|c|}
\hline Characteristics & ORR, No. (\%) & ${ }^{*} p$-value & ${ }^{g} \mathrm{OR}(95 \% \mathrm{Cl}), p$-value & DCR, No. (\%) & ${ }^{*} p$-value & ${ }^{9} \mathrm{OR}(95 \% \mathrm{Cl}), p$-value \\
\hline \multicolumn{7}{|l|}{ EGFR mutation subtype, №. (\%) } \\
\hline Exon 19 deletion & $52(76.5)$ & 0.265 & $2.27(0.47-11.01), 0.309^{\mathrm{a}}$ & $64(94.1)$ & 0.263 & $2.72(0.41-18.24), 0.302^{\mathrm{a}}$ \\
\hline Exon 21 L858R point mutation & $6(54.5)$ & & $0.40(0.03-5.21), 0.485^{b}$ & $9(81.8)$ & & $2.28(0.31-16.62), 0.420^{\mathrm{b}}$ \\
\hline Rare and complex mutation & $5(83.3)$ & & & $6(100)$ & & \\
\hline \multicolumn{7}{|c|}{ Baseline symptomatic brain metastases, No. (\%) } \\
\hline No & $49(81.7)$ & 0.014 & $4.51(1.45-14.00), 0.009^{\#}$ & $57(95.0)$ & 0.251 & $3.0(0.55-16.38), 0.205^{\#}$ \\
\hline Yes & $14(56.0)$ & & & $22(88.0)$ & & \\
\hline \multicolumn{7}{|l|}{ ECOG performance status, No. (\%) } \\
\hline $0-1$ & $49(71.0)$ & 0.175 & $0.27(0.05-1.44), 0.125^{\#}$ & $64(92.8)$ & 0.889 & $0.79(0.08-8.76), 0.835^{\#}$ \\
\hline $2-4$ & $14(87.5)$ & & & $15(93.8)$ & & \\
\hline \multicolumn{7}{|l|}{ Abnormal organ function, No. (\%) } \\
\hline No & $53(75.7)$ & 0.468 & $1.27(0.28-5.81), 0.755^{\#}$ & $64(91.4)$ & 0.585 & $0.57(0.07-4.97), 0.616^{\#}$ \\
\hline Yes & $10(66.7)$ & & & $15(100)$ & & \\
\hline \multicolumn{7}{|l|}{ Afatinib dose adjustment, No. (\%) } \\
\hline Dose reduced & $23(88.5)$ & 0.084 & $5.53(1.32-23.24), 0.019^{c}$ & $25(96.2)$ & 0.729 & $3.22(0.29-35.40), 0.339^{c}$ \\
\hline Dose increased & $8(80.0)$ & & $2.13(0.36-12.57), 0.404^{d}$ & $9(90.0)$ & & $1.30(0.11-15.02), 0.835^{d}$ \\
\hline Starting dose maintained & $32(65.3)$ & & & $45(91.8)$ & & \\
\hline \multicolumn{7}{|l|}{ Optimal afatinib dose, No. (\%) } \\
\hline Less than $40 \mathrm{mg}$ once daily & $40(78.4)$ & 0.156 & $2.03(0.59-6.94), 0.259^{e}$ & $47(92.2)$ & 0.836 & $0.88 ; 0.13-6.13,0.895^{\mathrm{e}}$ \\
\hline $40 \mathrm{mg}$ once daily & $19(63.3)$ & & & $28(29.3)$ & & \\
\hline $50 \mathrm{mg}$ once daily & $4(100)^{f}$ & & & $4(100)^{f}$ & & \\
\hline
\end{tabular}

Abbreviations: ORR objective response rate, DCR disease control rate, OR odd ratio, 95\% Cl 95\% confidence interval, EGFR epidermal growth factor receptor, ECOG Eastern Cooperative Oncology Group

${ }^{*} p$-value of Chi-square test

"second parameter was the reference group

a exon 19 deletion versus exon 21 L858R point mutation; ${ }^{\mathrm{b}}$ exon 19 deletion versus rare and complex mutations

cafatinib dose reduced versus starting dose maintained; ${ }^{d}$ afatinib dose increased versus starting dose maintained

eafatinib less than $40 \mathrm{mg}$ once daily versus $40 \mathrm{mg}$ once daily

fafatinib dose $50 \mathrm{mg}$ once daily not compared because of the small number of patients

${ }^{9}$ multivariate analysis with cox regression 


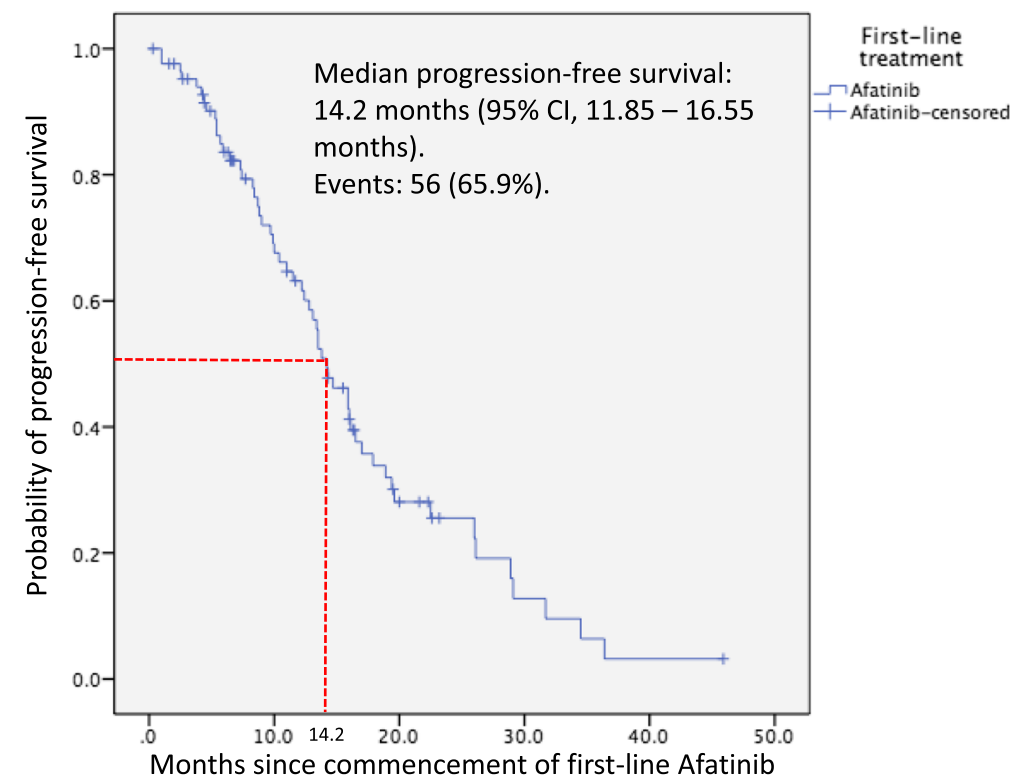

Fig. 2 Kaplan-Meir plot for progression-free survival of patients on first-line afatinib

Table 5 Univariate and multivariate analyses of progression-free survival according to clinical and treatment characteristics

\begin{tabular}{|c|c|c|c|c|c|c|}
\hline \multirow[t]{2}{*}{ Characteristics } & \multirow{2}{*}{$\begin{array}{l}\text { Patients, } \\
\text { No. (\%) }\end{array}$} & \multirow{2}{*}{$\begin{array}{l}\text { mPFS } \\
\text { (months) }\end{array}$} & \multicolumn{2}{|l|}{ Univariate analysis } & \multicolumn{2}{|c|}{ Multivariate analysis } \\
\hline & & & $\mathrm{HR}(95 \% \mathrm{Cl})$ & $p$-value & HR $(95 \% \mathrm{Cl})$ & $p$-value \\
\hline \multicolumn{7}{|l|}{ EGFR mutation subtype, No. (\%) } \\
\hline Exon 19 deletion & $68(80.0)$ & 16.0 & $0.31(0.14-0.71)^{\mathrm{a}}$ & 0.006 & $0.27(0.12-0.58)^{\mathrm{a}}$ & 0.001 \\
\hline Exon 21 L858R point mutation & $11(12.9)$ & 8.7 & $0.34(0.13-0.94)^{b}$ & 0.037 & $0.39(0.15-1.03)^{b}$ & 0.058 \\
\hline Rare and complex mutation & $6(7.1)$ & 9.0 & & & & \\
\hline \multicolumn{7}{|c|}{ Baseline symptomatic brain metastases, No. (\%) } \\
\hline No & $60(70.6)$ & 14.3 & $0.67(0.34-1.27)^{9}$ & 0.209 & $0.70(0.37-1.32)^{9}$ & 0.267 \\
\hline Yes & $25(29.4)$ & 13.5 & & & & \\
\hline \multicolumn{7}{|l|}{ ECOG performance status, No. (\%) } \\
\hline $0-1$ & $69(81.2)$ & 13.8 & $0.86(0.39-1.90)^{9}$ & 0.703 & $0.86(0.39-1.90)^{9}$ & 0.703 \\
\hline $2-4$ & $16(18.8)$ & 15.9 & & & & \\
\hline \multicolumn{7}{|l|}{ Abnormal organ function, No. (\%) } \\
\hline No & $70(82.4)$ & 14.3 & $0.53(0.25-1.09)^{9}$ & 0.086 & $0.50(0.25-1.00)^{9}$ & 0.050 \\
\hline Yes & $15(17.6)$ & 8.8 & & & & \\
\hline \multicolumn{7}{|l|}{ Afatinib dose adjustment, No. (\%) } \\
\hline Dose reduced & $26(30.6)$ & 15.9 & $0.93(0.44-1.99)^{c}$ & 0.854 & $0.72(0.39-1.34)^{c}$ & 0.301 \\
\hline Dose increased & $10(11.8)$ & 13.5 & $2.35(0.86-6.47)^{d}$ & 0.098 & $2.13(0.93-4.88)^{d}$ & 0.075 \\
\hline Starting dose maintained & $49(57.6)$ & 13.4 & & & & \\
\hline \multicolumn{7}{|l|}{ Optimal afatinib dose, No. (\%) } \\
\hline Less than $40 \mathrm{mg}$ once daily & $51(60.0)$ & 15.9 & $0.64(0.32-1.28)^{\mathrm{e}}$ & 0.209 & $0.47(0.21-1.08)^{e}$ & 0.075 \\
\hline $50 \mathrm{mg}$ once daily & $4(4.7)$ & 13.5 & $0.97(0.25-3.78)^{f}$ & 0.962 & $1.03(0.27-4.01)^{f}$ & 0.962 \\
\hline 40 mg once daily & $30(35.3)$ & 13.4 & & & & \\
\hline
\end{tabular}

Abbreviations: PFS progression-free survival, mPFS median PFS, HR hazard ratio, 95\% CI 95\% confidence interval, EGFR epidermal growth factor receptor, ECOG Eastern Cooperative Oncology Group

a exon 19 deletion versus exon 21 L858R point mutation; bexon 19 deletion versus rare and complex mutations

cafatinib dose reduced versus starting dose maintained; ${ }^{d}$ afatinib dose increased versus starting dose maintained

eafatinib less than $40 \mathrm{mg}$ once daily versus $40 \mathrm{mg}$ once daily; fafatinib $50 \mathrm{mg}$ once daily versus $40 \mathrm{mg}$ once daily

${ }^{g}$ the second group was the reference category in logistic regression analysis 


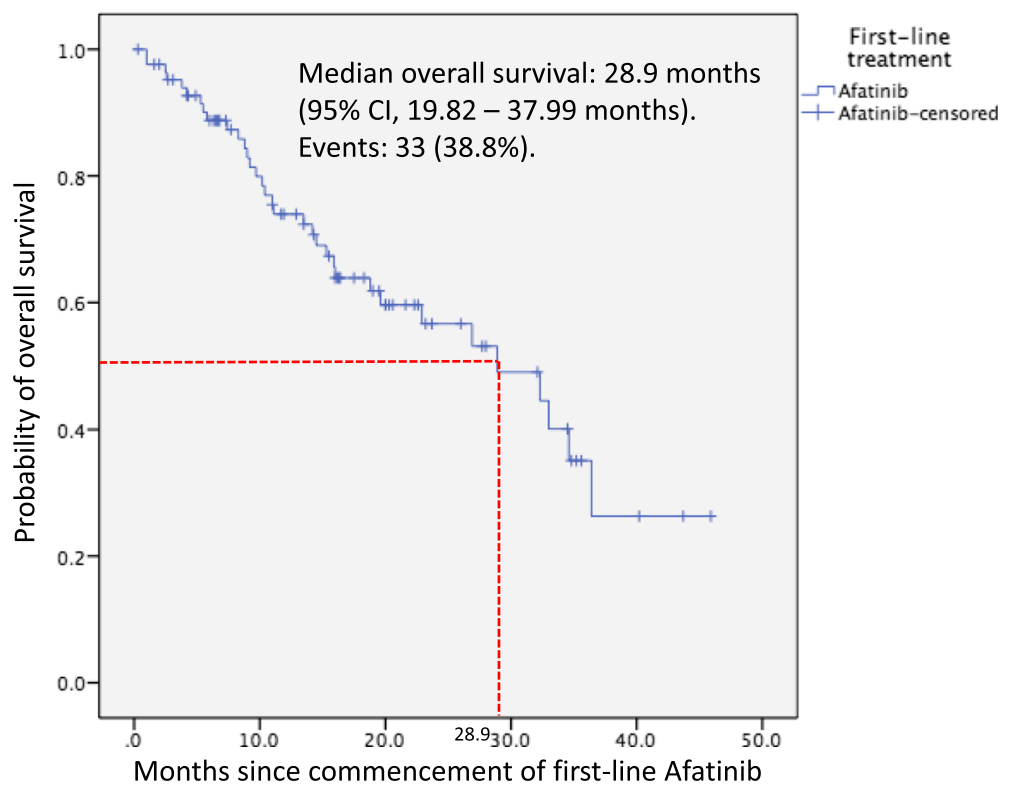

Fig. 3 Kaplan-Meir plot for overall survival of patients on first-line afatinib

\section{Resistance to afatinib}

Of 56 patients who experienced PD while on afatinib, only 31 (55.4\%) had PD after 31st December 2015 and were investigated for resistance mechanisms (Table 3). Exon $20 \mathrm{~T} 790 \mathrm{M}$ mutation was detected in $42.0 \%$ of the 31 patients, while no resistance mechanism could be identified in the remaining 58.0\%. T790 M mutation was detected exclusively in lung adenocarcinoma and was more frequent in female patients $(47.1 \%$ versus $35.7 \%$, $p=0.524)$.

\section{Side-effects of afatinib treatment}

One-fifth of the patients did not experience any side-effect; while one-tenth of patients experienced severe sideeffects while taking afatinib (Table 6). None of the patients had grade 4 side-effects. Acne (70.6\%) was the most common side-effect, followed by diarrhea $(54.1 \%)$, paronychia (40.0\%), stomatitis (27.1\%) and fatigue (16.5\%).

Table 6 Side-effects of first-line afatinib

\begin{tabular}{llllll}
\hline CTCAE grade & Grade 0 & Grade 1 & Grade 2 & Grade 3 & Grade 4 \\
\hline Diarrhea, No. (\%) & $39(45.9)$ & $25(29.4)$ & $17(20.0)$ & $4(4.7)$ & 0 \\
Stomatitis, No. (\%) & $62(72.9)$ & $13(15.3)$ & $8(9.4)$ & $2(2.4)$ & 0 \\
Acne/rash, No. (\%) & $25(29.4)$ & $35(41.2)$ & $20(23.5)$ & $5(5.9)$ & 0 \\
Paronychia, No. (\%) & $51(60.0)$ & $23(27.1)$ & $8(9.4)$ & $3(3.5)$ & 0 \\
Fatigue, No. (\%) & $71(83.5)$ & $13(15.3)$ & $1(1.2)$ & 0 & 0 \\
Side-effects, No (\%) & $17(20.0)$ & $59(69.4)$ & & $9(10.6)$ & \\
\hline
\end{tabular}

Abbreviations: CTCAE Common Terminology Criteria for Adverse Events

\section{Discussion}

In this study, patients with exon 19 deletion had significantly longer mPFS than those with exon 21 L858R point mutation. Most of the patients with rare or complex EGFR mutations demonstrated response to afatinib despite a shorter PFS than that of those with exon 19 deletion. On the other hand, patients with baseline symptomatic brain metastases did not have significantly shorter PFS compared to those without baseline symptomatic brain metastases despite their lower response rate to afatinib. Other unfavorable clinical characteristics frequently encountered in real-world practice such as poor ECOG performance status or abnormal organ function did not significantly affect the response rate to afatinib or PFS, which implies that afatinib works well even in these patients. Afatinib 40 or $30 \mathrm{mg}$ once daily seems to be the optimal maintenance dose which is effective for Malaysian patients and are uncommonly associated with severe side-effects. The need for dose reduction due to side-effects and the ability of the reduced dose to control the disease are reassuring to the treating clinicians. Symptomatic brain metastases causing failure to first-line afatinib were uncommon and acquired $T 790$ $M$ mutation is the most common identified resistance mechanism.

The demographic characteristics of our patients were consistent with previous reports, in which females, never smokers and Asians of Chinese ethnicity were predominant [17-19]. The majority of our patients harbored exon 19 deletion. This could have been due to selection bias whereby the treating clinicians were influenced by the mOS result of the LUX-Lung 3 and 
LUX-Lung 6 studies which favored first-line afatinib over cytotoxic chemotherapy among patients with exon 19 deletion $[7,8,20]$. The mPFS and ORR of patients receiving first-line afatinib in the present study correspond to that reported in randomized control trials (RCTs) (11.0-11.1 months; $56.0-70.0 \%)$ and other real-world studies (11.8-11.9 months; 67.2-78.4\%) [7-9, 21-24]. Another two real-world studies by Wu et al. [25] and Kim et al. [26] however, reported a much longer mPFS (21.0 and 19.1 months, respectively) among their patients receiving first-line afatinib. The former study included 14 patients who achieved a partial response or at least 6 months of stable disease when on first-line afatinib while the latter study only involved patients with ECOG 0-2 which could have contributed to the longer mPFS. Similar to the present study, Liang et al. [21], Tan et al. [22] Kim et al. [26] and Tanaka et al. [24] also consistently highlighted a longer mPFS and better ORR in patients with tumors harboring exon 19 deletion treated with first-line afatinib compared to those with exon $21 \mathrm{~L} 858 \mathrm{R}$ point mutation. In patients with complex or rare EGFR mutations treated with first-line afatinib, the present study and another three real-world studies reported a modest mPFS and ORR [21, 22, 27]. Similar beneficial response was not seen in such patients treated with first-generation EGFR-TKIs [27]. Contrary to the findings by Tan et al. [22], the present study did not find a significantly shorter mPFS among patients with symptomatic brain metastases receiving first-line afatinib [22]. This favorable outcome could be explained by the uniform afatinib starting dose of $40 \mathrm{mg}$ once daily and the comprehensive brain surgery or radiotherapy approach in the present study cohort. On the other hand, the findings of no difference in the survival and response rate among patients without symptomatic brain metastases when given afatinib $40 \mathrm{mg}$ or less than $40 \mathrm{mg}$ once daily in other studies are also in agreement with the present study [21, 23]. In a recent study by Hochmair et al. [28], exon 19 deletion, absence of active brain metastases and good ECOG performance status were shown to be associated with longer initial and post-progression treatment duration in a cohort of patients who developed T790M mutation following first-line afatinib treatment and subsequently treated with osimertinib. The median treatment duration for subgroups of patients with active brain metastases or poor ECOG performance status on first-line afatinib was 10.4 months in that study.

The present study and other real-world studies report a much lower incidence of grade 3 or 4 afatinib side-effects when compared to the incidence of $36.0-57.0 \%$ reported by RCTs [7-9, 21-23, 26]. This could have been due to the lower afatinib starting dose among patients without symptomatic brain metastases and rare or complex EGFR mutations in real-world studies. Early dose de-escalation in some patients before developing grade 3 side-effects in real-world practice could be another explanation. Nevertheless, the retrospective nature of these real-world studies could be a confounding factor for under reporting of drug side-effects. Upon PD on firstline afatinib, the incidence of new brain metastases in the present study was lower than that reported by Liang et al. [21] and Campo et al. [29] (18.6-19.0\%). The incidence of acquired $T 790 \mathrm{M}$ mutation was comparable to that reported in the literature (32.1-47.6\%) but less than that reported in studies involving first-generation EGFRTKIs (49.0-63.0\%) [21, 24-26, 30-33].

This study is among the very few real-world analyses that include patients with unfavorable characteristics such as rare or complex EGFR mutations, symptomatic brain metastases, poor ECOG performance status and inadequate organ function. These characteristics have been routinely excluded in RCTs but are common challenges in the real-world. The result of our study therefore further complements the existing information on afatinib from RCTs. Another strength of our study is that we attempted to explore the efficacy of afatinib in various doses and highlight the non-inferior response among patients with symptomatic brain metastases on afatinib $40 \mathrm{mg}$ once daily.

This study has several limitations. Its retrospective nature might have led to possible errors in data recording or measurement. The number of patients with exon 21 $L 858 R$ point mutation was disproportionately small. Only about half of the patients with PD were investigated for acquired resistance which was limited to $T 790$ $M$ mutation and histologic transformation. Fatigue is a subjective symptom which could have been underreported by the patients during clinic visits.

\section{Conclusions}

Afatinib is an effective first-line treatment for patients with EGFR-mutant NSCLC. It is associated with good response rate and prolonged PFS. Patients with unfavorable clinical characteristics such as rare or complex EGFR mutations, symptomatic brain metastases, poor ECOG performance status, and inadequate organ function also benefit from first-line afatinib treatment. The side-effects of afatinib are moderate and T790 M mutation is the most common resistance mechanism identified.

\section{Abbreviations}

Cl: Confidence interval; CT: Computed tomography; CTCAE v4.0: Common Terminology Criteria for Adverse Events version 4; DCR: Disease control rate; ECOG: Eastern Cooperative Oncology Group; EGFR: Epidermal growth factor receptor; mOS: Median overall survival; mPFS: Median progression-free survivals; NSCLC: Non-small cell lung cancer; OR: Odds ratio; ORR: Objective response rate; $\mathrm{PCR}$ : Polymerase chain reaction; SD: Standard deviation; TAP: Thorax, abdomen and pelvis; TKI: Tyrosine kinase inhibitor 


\section{Acknowledgements}

We want to express our gratitude to all the patients who had participated in the study.

\section{Authors' contributions}

All the authors including GH, CC, AA, MIAW, MMA, YF, SH, AZ, KLa, KLe, JL, $M M Y, E L, Y T$ and $C L$ designed the study and involved in the data acquisition. $C C, E L, Y T$ and $C L$ performed the data analysis and interpreted the results. $\mathrm{CC}, \mathrm{CL}$ and $\mathrm{GH}$ drafted the article and critically revising it. All the authors approved the final version of the articles and agreed to be accountable for the work.

\section{Funding}

No funding.

\section{Availability of data and materials}

The datasets used and/or analyzed during the current study are available from the corresponding author on reasonable request.

\section{Ethics approval and consent to participate}

This study was approved by respective hospitals' ethics committee of University Malaya Medical Center (MECID.No2018224-6046), Subang Jaya Medical Centre (MECID.No201612.6), and Pantai Hospital Kuala Lumpur (MECID.Nomms/MDAC/9397-OGM). The study ethic for Hospital Tengku Ampuan Afzuan Kuantan, Beacon International Specialist Centre and Gleneagles Hospital Penang was approved by National Medical Research Center, Ministry of Health Malaysia [MRECID.NoKKM.NIHSEC.P18-800 (6)]. All with waiver of informed consent.

\section{Consent for publication}

Not applicable.

\section{Competing interests}

The authors declare that they have no competing interests.

\section{Author details}

${ }^{1}$ Department of Clinical Oncology, Faculty of Medicine, University of Malaya, Kuala Lumpur, Malaysia. ${ }^{2}$ Department of Medicine, Faculty of Medicine and Health Science, University Malaysia Sarawak, Kota Samarahan, Sarawak, Malaysia. ${ }^{3}$ Beacon International Specialist Centre, Kuala Lumpur, Malaysia. ${ }^{4}$ Subang Jaya Medical Centre, Kuala Lumpur, Malaysia. ${ }^{5}$ Hospital Tengku Ampuan Afzan, Kuantan, Malaysia. ${ }^{6}$ Gleneagles Hospital, Penang, Malaysia. ${ }^{7}$ Pantai Hospital, Kuala Lumpur, Malaysia. ${ }^{8}$ Department of Medicine, Faculty of Medicine, University of Malaya, Kuala Lumpur, Malaysia.

\section{Received: 2 April 2019 Accepted: 29 August 2019}

Published online: 09 September 2019

\section{References}

1. Planchard D, Popat S, Kerr K, Novello S, Smit EF, Faivre-Finn C, et al. Metastatic non-small cell lung cancer: ESMO Clinical Practice Guidelines for diagnosis, treatment and follow-upt. Ann Oncol. 2018;29(Supplement_4):iv192-iv237.

2. Mok TS, Wu Y-L, Thongprasert S, Yang C-H, Chu D-T, Saijo N, et al. Gefitinib or carboplatin-paclitaxel in pulmonary adenocarcinoma. N Engl J Med. 2009;361(10):947-57.

3. Maemondo M, Inoue A, Kobayashi K, Sugawara S, Oizumi S, Isobe H, et al. Gefitinib or chemotherapy for non-small-cell lung cancer with mutated EGFR. N Engl J Med. 2010;362(25):2380-8.

4. Mitsudomi T, Morita S, Yatabe Y, Negoro S, Okamoto I, Tsurutani J, et al. Gefitinib versus cisplatin plus docetaxel in patients with non-small-cell lung cancer harbouring mutations of the epidermal growth factor receptor (WJTOG3405): an open label, randomised phase 3 trial. Lancet Oncol. 2010; 11(2):121-8.

5. Zhou C, Wu YL, Chen G, Feng J, Liu XQ, Wang C, et al. Erlotinib versus chemotherapy as first-line treatment for patients with advanced EGFR mutation-positive non-small-cell lung cancer (OPTIMAL, CTONG-0802): a multicentre, open-label, randomised, phase 3 study. Lancet Oncol. 2011; 12(8):735-42.

6. Rosell R, Carcereny E, Gervais R, Vergnenegre A, Massuti B, Felip E, et al. Erlotinib versus standard chemotherapy as first-line treatment for European patients with advanced EGFR mutation-positive non-small-cell lung cancer
(EURTAC): a multicentre, open-label, randomised phase 3 trial. Lancet Oncol. 2012;13(3):239-46.

7. Sequist LV, Yang JC-H, Yamamoto N, O'Byrne K, Hirsh V, Mok T, et al. Phase III study of Afatinib or Cisplatin plus Pemetrexed in patients with metastatic lung adenocarcinoma with EGFR mutations. J Clin Oncol. 2013;31(27):3327-34.

8. Wu YL, Zhou C, Hu CP, Feng J, Lu S, Huang Y, et al. Afatinib versus cisplatin plus gemcitabine for first-line treatment of Asian patients with advanced non-small-cell lung cancer harbouring EGFR mutations (LUX-lung 6): an open-label, randomised phase 3 trial. Lancet Oncol. 2014;15(2):213-22.

9. Park K, Tan EH, O'Byrne K, Zhang L, Boyer M, Mok T, et al. Afatinib versus gefitinib as first-line treatment of patients with EGFR mutation-positive nonsmall-cell lung cancer (LUX-lung 7): a phase 2B, open-label, randomised controlled trial. Lancet Oncol. 2016;17(5):577-89.

10. Soria J-C, Felip E, Cobo M, Lu S, Syrigos K, Lee KH, et al. Afatinib versus erlotinib as second-line treatment of patients with advanced squamous cell carcinoma of the lung (LUX-lung 8): an open-label randomised controlled phase 3 trial. Lancet Oncol. 2015;16(8):897-907.

11. Li D, Ambrogio L, Shimamura T, Kubo S, Takahashi M, Chirieac LR, et al. BIBW2992, an irreversible EGFR/HER2 inhibitor highly effective in preclinical lung cancer models. Oncogene. 2008;27(34):4702-11.

12. Solca F, Dahl G, Zoephel A, Bader G, Sanderson M, Klein C, et al. Target binding properties and cellular activity of afatinib (BIBW 2992), an irreversible ErbB family blocker. J Pharmacol Exp Ther. 2012;343(2):342-50.

13. Centers for Disease Control and Prevention (CDC). Cigarette smoking among adults - United States, 1992, and changes in the definition of current cigarette smoking. MMWR Morb Mortal Wkly Rep. 1994;43(19):342-6.

14. National Cancer Institute. Common Terminology Criteria for Adverse. Events v.3.0and v.4.0 (CTCAE). Available from: http://ctep.cancer.gov/protocol. Development/electronic_applications/ctc.htm. [February 10, 2019].

15. Edge SB, Compton CC. The American Joint Committee on cancer: the 7th edition of the AJCC cancer staging manual and the future of TNM. Ann Surg Oncol. 2010;17(6):1471-4.

16. Eisenhauer EA, Therasse P, Bogaerts J, Schwartz LH, Sargent D, Ford R, et al. New response evaluation criteria in solid tumours: revised RECIST guideline (version 1.1). Eur J Cancer (Oxford, England : 1990.). 2009;45(2):228-47.

17. Shigematsu H, Lin L, Takahashi T, Nomura M, Suzuki M, Wistuba II, et al. Clinical and biological features associated with epidermal growth factor receptor gene mutations in lung cancers. J Natl Cancer Inst. 2005;97(5): $339-46$.

18. Tsao AS, Tang XM, Sabloff B, Xiao L, Shigematsu H, Roth J, et al. Clinicopathologic characteristics of the EGFR gene mutation in non-small cell lung cancer. J Thorac Oncol. 2006;1(3):231-9.

19. Rosell R, Moran T, Queralt C, Porta R, Cardenal F, Camps C, et al. Screening for epidermal growth factor receptor mutations in lung cancer. $\mathrm{N}$ Engl J Med. 2009;361(10):958-67.

20. Yang JC, Wu YL, Schuler M, Sebastian M, Popat S, Yamamoto N, et al. Afatinib versus cisplatin-based chemotherapy for EGFR mutation-positive lung adenocarcinoma (LUX-lung 3 and LUX-lung 6): analysis of overall survival data from two randomised, phase 3 trials. Lancet Oncol. 2015;16(2):141-51.

21. Liang SK, Hsieh MS, Lee MR, Keng LT, Ko JC, Shih JY. Real-world experience of afatinib as a first-line therapy for advanced EGFR mutation-positive lung adenocarcinoma. Oncotarget. 2017;8(52):90430-43.

22. Tan W-L, Ng QS, Lim C, Tan EH, Toh CK, Ang M-K, et al. Influence of afatinib dose on outcomes of advanced EGFR-mutant NSCLC patients with brain metastases. BMC Cancer. 2018;18(1):1198.

23. Liu CY, Wang CL, Li SH, Hsu PC, Chen CH, Lin TY, et al. The efficacy of $40 \mathrm{mg}$ versus dose de-escalation to less than $40 \mathrm{mg}$ of afatinib (Giotrif) as the first-line therapy for patients with primary lung adenocarcinoma harboring favorable epidermal growth factor mutations. Oncotarget. 2017;8(57):97602-12.

24. Tanaka K, Nosaki K, Otsubo K, Azuma K, Sakata S, Ouchi H, et al. Acquisition of the T790M resistance mutation during afatinib treatment in EGFR tyrosine kinase inhibitor-naive patients with non-small cell lung cancer harboring EGFR mutations. Oncotarget. 2017;8(40):68123-30.

25. Wu SG, Liu YN, Tsai MF, Chang YL, Yu CJ, Yang PC, et al. The mechanism of acquired resistance to irreversible EGFR tyrosine kinase inhibitor-afatinib in lung adenocarcinoma patients. Oncotarget. 2016;7(11):12404-13.

26. Kim Y, Sun J, Park K, Park SE, Lee S, Ahn M, et al. P3.01-023 first-line Afatinib for non-small cell lung Cancer in real world practice. J Thorac Oncol. 2017; 12(11):S2209. 
27. Shen YC, Tseng GC, Tu CY, Chen WC, Liao WC, Chen WC, et al. Comparing the effects of afatinib with gefitinib or Erlotinib in patients with advanced-stage lung adenocarcinoma harboring non-classical epidermal growth factor receptor mutations. Lung Cancer (Amsterdam, Netherlands). 2017;110:56-62.

28. Hochmair MJ, Morabito A, Hao D, Yang CT, Soo RA, Yang JC, et al. Sequential treatment with afatinib and osimertinib in patients with EGFR mutation-positive non-small-cell lung cancer: an observational study. Future Oncol (London, England). 2018;14(27):2861-74.

29. Campo M, Gerber D, Gainor JF, Heist RS, Temel JS, Shaw AT, et al. Acquired resistance to first-line Afatinib and the challenges of prearranged progression biopsies. J Thorac Oncol. 2016;11(11):2022-6.

30. Oxnard GR, Arcila ME, Sima CS, Riely GJ, Chmielecki J, Kris MG, et al. Acquired resistance to EGFR tyrosine kinase inhibitors in EGFR-mutant lung cancer: distinct natural history of patients with tumors harboring the T790M mutation. Clin Cancer Res. 2011;17(6):1616-22.

31. Yu HA, Arcila ME, Rekhtman N, Sima CS, Zakowski MF, Pao W, et al. Analysis of tumor specimens at the time of acquired resistance to EGFR-TKI therapy in 155 patients with EGFR-mutant lung cancers. Clin Cancer Res. 2013;19(8):2240-7.

32. Sun JM, Ahn MJ, Choi YL, Ahn JS, Park K. Clinical implications of T790M mutation in patients with acquired resistance to EGFR tyrosine kinase inhibitors. Lung Cancer (Amsterdam, Netherlands). 2013;82(2):294-8.

33. Kuiper JL, Heideman DA, Thunnissen E, Paul MA, van Wijk AW, Postmus PE, et al. Incidence of T790M mutation in (sequential) rebiopsies in EGFRmutated NSCLC-patients. Lung Cancer (Amsterdam, Netherlands). 2014; 85(1):19-24

\section{Publisher's Note}

Springer Nature remains neutral with regard to jurisdictional claims in published maps and institutional affiliations.

Ready to submit your research? Choose BMC and benefit from:

- fast, convenient online submission

- thorough peer review by experienced researchers in your field

- rapid publication on acceptance

- support for research data, including large and complex data types

- gold Open Access which fosters wider collaboration and increased citations

- maximum visibility for your research: over $100 \mathrm{M}$ website views per year

At BMC, research is always in progress.

Learn more biomedcentral.com/submissions 